\title{
Osteoporose em caprinos ${ }^{1}$
}

\author{
Fábio B. Rosa ${ }^{2}$, Glauco J.N. Galiza², Ricardo B. Lucena², Taiara M. Silva ${ }^{3}$, Rafaela A. \\ Caprioli $^{3}$, Claudio S.L. Barros ${ }^{4}$, Rafael A. Fighera ${ }^{4}$ e Glaucia D. Kommers ${ }^{4 *}$
}

\begin{abstract}
Rosa F.B., Galiza G.J.N., Lucena R.B., Silva T.M., Caprioli R.A., Barros C.S.L., Fighera R.A. \& Kommers G.D. 2013. [Osteoporosis in goats.] Osteoporose em caprinos. Pesquisa Veterinária Brasileira 33(4):483-489. Laboratório de Patologia Veterinária, Departamento de Patologia, Universidade Federal de Santa Maria, Camobi, Santa Maria, RS 97105-900, Brazil. E-mail: glaukommers@yahoo.com

A study of cases of osteoporosis in goats diagnosed in the Laboratório de Patologia Veterinária, Universidade Federal de Santa Maria, Rio Grande do Sul state, Brazil, was performed. The epidemiology, clinicopathological changes and possible pathogenetic mechanisms were determined and discussed. Five goats, females, mixed breed, with six months to six years of age were affected. The goats were kept on natural pasture without supplemental feed and under overcrowding condition. The main clinical signs were weight loss, limited mobility, and recumbence for long periods. The main gross bone changes, observed on the cutting surface, were depletion of cancellous bone (porosity) and marked reduction in the thickness of the cortical bone. Severe serous atrophy of medullary adipose tissue was also observed. Microscopically, in the evaluated regions (proximal humerus, distal radius, distal femur, proximal tibia and lumbar vertebral bodies), moderate to marked reduction in the number and thickness of bone trabeculae in the epiphyses and metaphyses of long bones and in the vertebral bodies were observed. The clinicopathological features indicated that the osteoporosis observed was probably caused by malnutrition. The bone changes (decrease in the number and thickness of trabeculae of cancellous bone) suggest that both mechanisms, poor bone formation and increased bone resorption, contributed to the occurrence of osteoporosis in the goats of this study.
\end{abstract}

INDEX TERMS: Osteoporosis, metabolic and nutritional bone diseases, diseases of goats, veterinary pathology.

RESUMO.- Foi realizado um estudo de casos de osteoporose em caprinos provenientes de uma propriedade na área de abrangência do LPV-UFSM, determinando a epidemiologia, o quadro clínico-patológico e discutindo os prováveis mecanismos patogenéticos. Cinco cabras, fêmeas, SRD, de seis meses a seis anos de idade foram afetadas. As cabras eram mantidas em campo nativo, sem suplementação com

\footnotetext{
${ }^{1}$ Recebido em 9 de março de 2013.

Aceito para publicação em 2 de abril de 2013.

Parte da Dissertação de Mestrado do primeiro autor.

${ }^{2}$ Programa de Pós-Graduação em Medicina Veterinária, área de concentração em Patologia Veterinária, Centro de Ciências Rurais (CCR), Universidade Federal de Santa Maria (UFSM), Camobi, Santa Maria, RS 97105900, Brasil.

${ }^{3}$ Curso de Medicina Veterinária, CCR-UFSM, Santa Maria, RS.

${ }^{4}$ Laboratório de Patologia Veterinária, Departamento de Patologia, Centro de Ciências da Saúde, UFSM, Av. Roraima 1000, Santa Maria, RS 97105900. *Autor para correspondência: glaukommers@yahoo.com
}

ração e sob superlotação. Os principais sinais clínicos foram emagrecimento, dificuldade de locomoção e permanência em decúbito por longos períodos. As principais alterações macroscópicas nos ossos examinados foram vistas nas superfícies de corte e caracterizavam-se por depleção do osso esponjoso (porosidade) e redução acentuada da espessura do osso cortical. Havia também marcada atrofia serosa da gordura da medula óssea. Microscopicamente, nas regiões avaliadas (úmero proximal, rádio distal, fêmur distal, tíbia proximal e corpos das vértebras lombares) foi observada redução moderada a acentuada do número e da espessura das trabéculas ósseas nas epífises e metáfises dos ossos longos e nos corpos vertebrais. Os achados clínico-patológicos indicaram que a osteoporose observada provavelmente foi causada pela desnutrição. As alterações ósseas (diminuição no número e na espessura das trabéculas do osso esponjoso) sugerem que ambos os mecanismos, má formação óssea e reabsorção óssea aumentada, contribu- 
íram para a ocorrência de osteoporose nos caprinos deste estudo.

TERMOS DE INDEXAÇÃO: Osteoporose, doenças ósseas metabólicas e nutricionais, doenças de caprinos, patologia veterinária.

\section{INTRODUÇÃO}

Osteoporose é a doença óssea metabólica mais comum em humanos e é caracterizada por um aumento da porosidade do esqueleto resultante da redução da massa óssea, levando à fragilidade mecânica e, consequente, predisposição às fraturas (Rosenberg 2005). A osteoporose representa um desequilíbrio entre a formação e a reabsorção ósseas, resultando em osso que é estruturalmente normal, mas com reduzida resistência à ruptura (Thompson 2007). Este equilíbrio negativo entre formação e reabsorção ósseas é reconhecido como uma parte normal do processo de envelhecimento em humanos e animais. Entretanto, há várias condições que aceleram a perda óssea, causando depleção prematura do esqueleto (Carlson \& Weisbrode 2012).

0 distúrbio pode ser localizado em certa região ou osso, como na osteoporose por desuso ou imobilização de um membro, ou pode envolver todo o esqueleto, como a manifestação de uma doença metabólica (Carlson \& Weisbrode 2012). Em humanos, costuma-se dividir a osteoporose em primária ou secundária. Na osteoporose primária incluem-se a senil e a pós-menopausal, sendo essas as formas mais comuns de osteoporose em humanos (Rosenberg 2005). A osteoporose secundária é causada por fatores externos como desuso, imobilização, ovariectomia, tratamento prolongado com glicocorticoides e desnutrição (Adachi 2009).

A maior parte dos casos de osteoporose em animais, especialmente em animais de fazenda, é de origem nutricional e pode ser devida a um nutriente específico, como cálcio, fósforo, ou cobre, ou à má nutrição, em que há consumo restrito de ração balanceada (Thompson 2007). A má nutrição é relativamente comum em animais de fazenda em áreas propensas a secas ou devido à superlotação, quando o crescimento das pastagens está abaixo das expectativas. A osteoporose também pode ser causada por parasitismo intestinal acentuado, por complicação de doença inflamatória intestinal e induzida por corticosteroide (Stover 2006).

Muitos casos de osteoporose em animais não são detectados, mesmo na necropsia, pois a forma externa dos ossos não está alterada, a menos que ocorra fratura patológica. Ocorrência de fraturas sem trauma excessivo ou aumento de fraturas no rebanho são indicadores de osteoporose (Egermann et al. 2005). Apesar da importância da doença, há poucos estudos sobre osteoporose em animais de produção no Brasil. Recentemente foi realizado um estudo em búfalos na Ilha de Marajó (Pereira \& Cardoso 2010). Em caprinos os dados são ainda mais escassos. Braun et al. (2009) recentemente relataram a primeira descrição de osteoporose espontânea em caprinos associada à deficiência de cálcio e fósforo. Entretanto, há numerosas pesquisas sobre osteoporose que utilizam animais como modelo experimental, incluindo roedores, coelhos, cães, primatas (Jee \& Yao 2001), ovinos (Zarrinkalam et al. 2009, Ding et al. 2010, Dvorak et al. 2010, Veigel et al. 2011) e caprinos

(Li et al. 2012).

Os objetivos deste estudo foram relatar a ocorrência de osteoporose em caprinos em uma propriedade na área de abrangência do Laboratório de Patologia Veterinária da Universidade Federal de Santa Maria (LPV-UFSM), determinando a epidemiologia e o quadro clínico-patológico desta doença. Mecanismos patogenéticos foram também abordados.

\section{MATERIAL E MÉTODOS}

Um caprino, sem raça definida (SRD), fêmea, de oito meses de idade (Cabra 1), de uma propriedade com 26 caprinos, foi submetido ao LPV-UFSM para a realização da necropsia. Dados adicionais relacionados à epidemiologia e aos sinais clínicos apresentados por outros caprinos afetados foram obtidos por meio de uma visita à propriedade. Foi realizada coleta de amostras de sangue de quatro cabras com sinais clínicos semelhantes (Cabras 2, 3, 4 e 5). A partir das amostras de sangue, os níveis de cálcio (Ca), fósforo (P) e hemoglobina $(\mathrm{Hb})$ e as atividades séricas de fosfatase alcalina (FA) e da creatinofosfoquinase (CK) foram determinados. Valores de referência para os parâmetros bioquímicos foram baseados em dados previamente estabelecidos para a espécie caprina (Kaneko et al. 2008, Braun et al. 2009). Também foi realizada coleta de fezes e subsequentemente contagens de ovos de nematódeos por grama de fezes (OPG) (individualmente para cada cabra), pelo método de Gordon \& Withlock (1939); e cultivo de larvas (para as Cabras 2-5), pelo método de Roberts \& O’Sullivan (1950).

A Cabra 1 teve morte espontânea; as Cabras 2-5 foram submetidas à eutanásia devido à acentuada dificuldade de locomoção e desnutrição. Na necropsia, foram coletados fragmentos de vários órgãos (dos cinco caprinos afetados), os ossos longos (úmero, rádio, fêmur, tíbia, metacarpo e metatarso), as vértebras lombares, a mandíbula, a escápula e o ílio (das Cabras 2-5). Da Cabra 1 foram coletados somente o úmero e o fêmur. Os ossos foram seccionados longitudinalmente em serra-fita. Os tecidos foram fixados (em formol neutro a 10\%), processados e corados rotineiramente para histopatologia. Para a descalcificação do tecido ósseo foi utilizado descalcificador à base de ácido fórmico, citrato de sódio e água.

Para a avaliação histopatológica do tecido ósseo foram analisadas seções dos seguintes ossos: úmero proximal, rádio distal, fêmur distal, tíbia proximal e corpos das vértebras lombares. Como comparativo, foram utilizadas seções dos mesmos ossos de uma cabra em bom estado nutricional e sem alterações ósseas macroscópicas ou microscópicas. Os casos de osteoporose deste relato foram mencionados em um estudo retrospectivo das doenças de caprinos diagnosticadas no LPV-UFSM em 48 anos (Rosa et al. 2013).

\section{RESULTADOS}

Osteoporose foi diagnosticada em cinco cabras em uma propriedade com alta densidade populacional, com cabras de diferentes idades alojadas nas mesmas instalações e com baixa condição sanitária. A alimentação dos caprinos era à base de pastoreio em campo nativo; não era fornecida ração balanceada. Os animais afetados estavam magros e com dificuldade de locomoção, permanecendo grande parte do tempo em decúbito. A idade e os sinais clínicos apresentados estão sumarizados no Quadro 1. Dados referentes ao $\mathrm{OPG}$, hemoglobina e testes bioquímicos encontram-se no Quadro 2. Na coprocultura foram detectadas larvas de 
Quadro 1. Idade e sinais clínicos de cinco caprinos, fêmeas, sem raça definida, afetados por osteoporose

\begin{tabular}{|c|c|c|}
\hline Cabras & s Idade & Sinais clínicos \\
\hline 1 & 8 meses & $\begin{array}{l}\text { Apatia, fraqueza, emagrecimento, andar rígido, claudica- } \\
\text { ção e decúbito. }\end{array}$ \\
\hline 2 & 6 anos & $\begin{array}{l}\text { Palidez das mucosas oral e ocular, apatia } \\
\text { to, fraqueza, dificuldade de locomoção, } \\
\text { bito. }\end{array}$ \\
\hline 3 & 6 meses & $\begin{array}{l}\text { Anorexia, fraqueza, emagrecimento, diarreia, dificuldade } \\
\text { em manter-se em estação e decúbito. }\end{array}$ \\
\hline 4 & $10 n$ & $\begin{array}{l}\text { Palidez das mucosas oral e ocular, apatia, fraqueza, ema- } \\
\text { grecimento e dificuldade de locomoção. }\end{array}$ \\
\hline 5 & 10 & Palidez das mucosas oral e ocular, emagrecimento e fra- \\
\hline
\end{tabular}

Quadro 2. Parâmetros sanguíneos e parasitológicos de caprinos afetados por osteoporose

\begin{tabular}{lccccc}
\hline Parâmetros avaliados & \multicolumn{3}{c}{ Cabras } & \multicolumn{2}{c}{ Valor de referência } \\
\cline { 2 - 5 } & 2 & 3 & $\mathbf{4}$ & $\mathbf{5}$ & \\
\hline OPG & 19.700 & 11.200 & 3.800 & 3.700 & $-^{\mathrm{a}}$ \\
Hemoglobina (g/dL) & 2,1 & 3,1 & 5,2 & 4,1 & $8-12^{\mathrm{b}}$ \\
Ca (mg/dL) & 6,8 & 8,8 & 8,7 & 9,1 & $8,9-11,7^{\mathrm{b}}$ \\
P (mg/dL) & 6,1 & 4,8 & 2,7 & 5,6 & $4,2-9,1^{\mathrm{b}}$ \\
CK (U/L) & 523 & 352 & 118 & 178 & $86-208^{\mathrm{c}}$ \\
FA (U/L) & 70 & 20 & 60 & 37 & $93-387^{\mathrm{b}}$
\end{tabular}

$\overline{\mathrm{OPG}}=$ ovos por fezes; $\mathrm{Ca}=$ cálcio; $\mathrm{P}=$ fósforo; $\mathrm{CK}=$ creatinofosfoquinase; $\mathrm{FA}=$ fosfatase alcalina. ${ }^{\mathrm{a}}$ 0-50 (baixo parasitismo), 50-200 (moderado parasitismo), acima de 200 (alto parasitismo), segundo Gordon \& Wi-

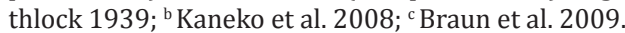

\section{Quadro 3. Alterações ósseas macroscópicas observadas em caprinos com osteoporose}

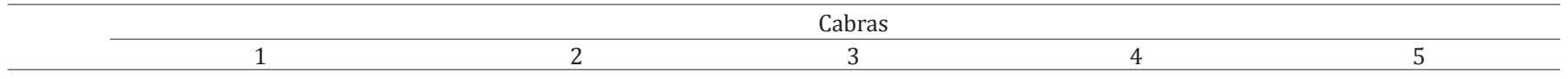

Úmero Depleção leve do osso espon- Depleção acentuada do osso Depleção leve do osso Cavitação focal na epífise e Depleção leve do osso joso metafisário e epifisário esponjoso metafisário proxi- esponjoso metafisário depleção moderada do osso esponjoso metafisário de proximal. 0 osso cortical es- mal e moderada no distal. De- proximal. Depleção mo- esponjoso metafisário proxi- ambas as extremidades. tava acentuadamente mais pleção leve do osso esponjoso derada do osso espon- mal. Osso cortical mais fino. Osso cortical mais fino. fino e havia atrofia serosa da em ambas as epífises. joso metafisário distal. gordura medular.

Rádio Não examinado.

Depleção acentuada do osso Depleção moderada a Depleção acentuada do osso Depleção moderada do esponjoso metafisário e dia- acentuada do osso es- esponjoso metafisário de am- osso esponjoso metafisáfisário de ambas as extremi- ponjoso metafisário basas extremidades.Ossocor- rio de ambas as extremidades. Atrofia gelatinosa da proximal com cavita- tical mais fino. dades. gordura medular. ção focal.

Fêmur Cavitação focalmente exten- Depleção acentuada do osso Depleção leve do osso Depleção leve do osso espon- Depleção leve do osso sa do osso esponjoso meta- esponjoso em ambas as extre- esponjoso metafisário joso metafisário de ambas esponjoso metafisário de fisário e epifisário proximal. midades. Osso cortical mais de ambas as extremida- as extremidades. Depleção am-bas as extremidades. Depleção do osso esponjoso fino. Atrofia serosa da gordura des. A-trofia gelatinosa moderada do osso esponjoso Osso cortical acentuadametafisário distal. Osso cor- me-dular. $\quad$ da gordura medular. epifisário proximal, com uma mente mais fino. tical acentuadamente fino. cavitação. Osso cortical acentuadamente mais fino.

Tíbia Não examinado.

Depleção acentuada do osso Depleção leve do osso Depleção moderada a acen- Depleção acentuada do esponjoso metafisário e diafi- esponjoso na metáfise tuada do osso esponjoso me- osso esponjoso metafisásário de ambas as extremida- proximal. tafisário de ambas as extre- rio de ambas as extremides. Atrofia gelatinosa da gordura medular. midades. Osso cortical mais dades. fino.

Vértebra Não examinado. Depleção leve a moderada do Depleção moderada do Depleção leve a moderada do Depleção leve do osso eslombar osso esponjoso. osso esponjoso. osso esponjoso. ponjoso.
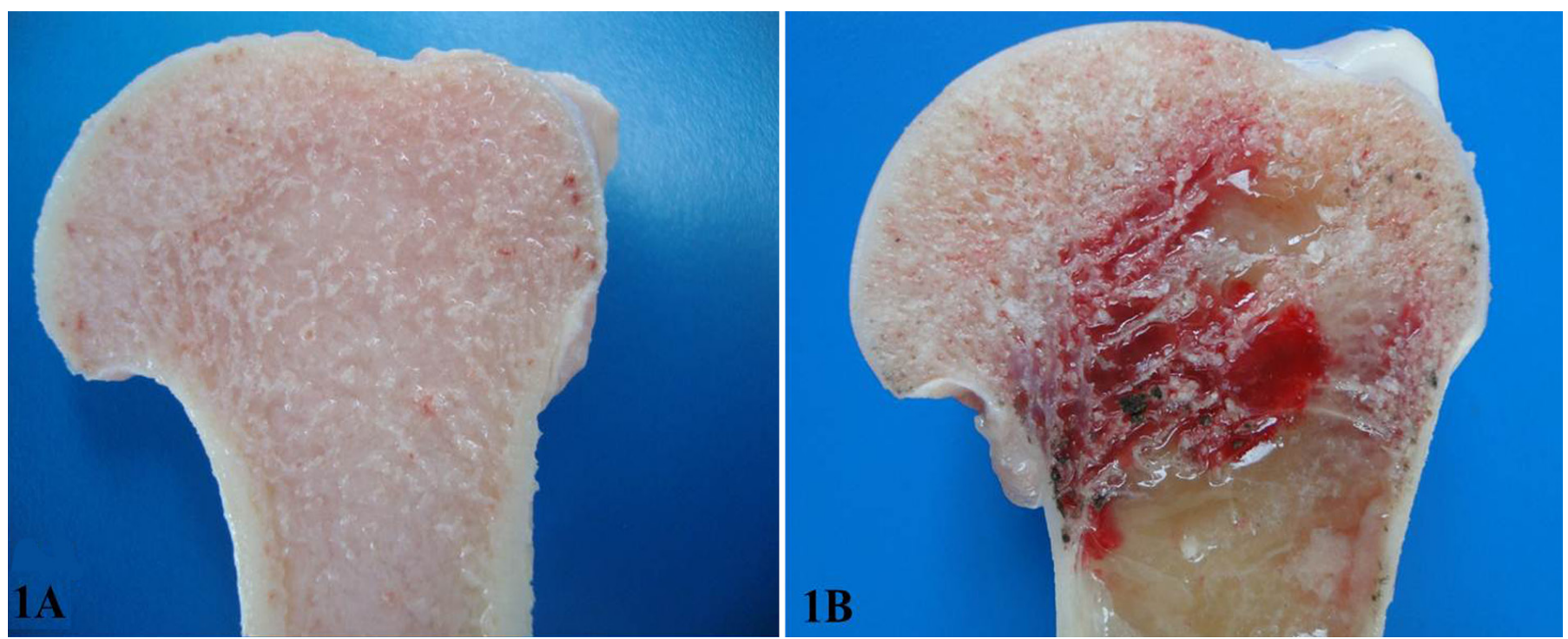

Fig.1. Osteoporose em caprino. Úmero proximal. (A) Cabra normal. (B) Cabra 2, apresentando marcada depleção do osso esponjoso epifisário e metafisário, osso cortical fino e atrofia serosa da gordura da medula óssea. 


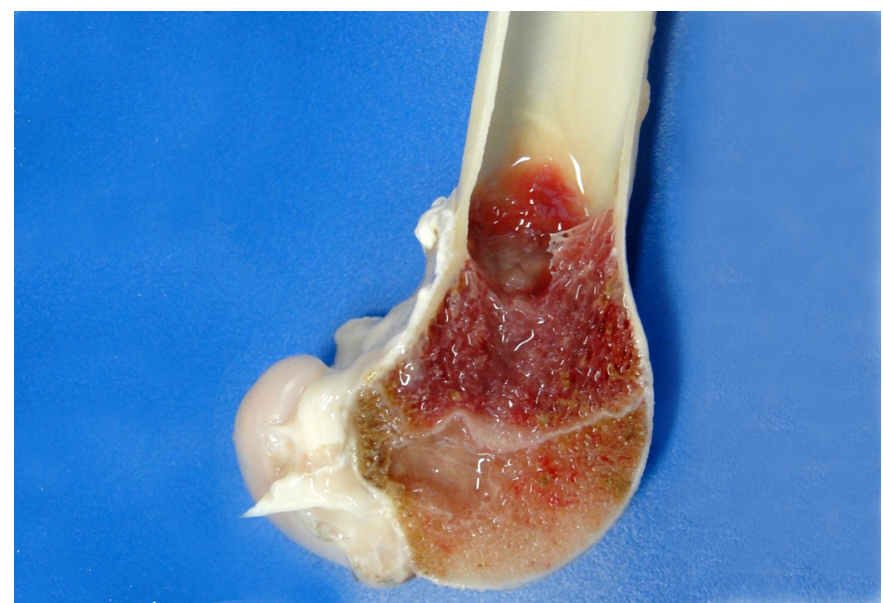

Fig.2. Osteoporose em caprino. Fêmur distal. Cabra 1, apresentando marcada depleção do osso esponjoso, com cavitações multifocais na epífise e metáfise. 0 osso cortical está acentuadamente fino.

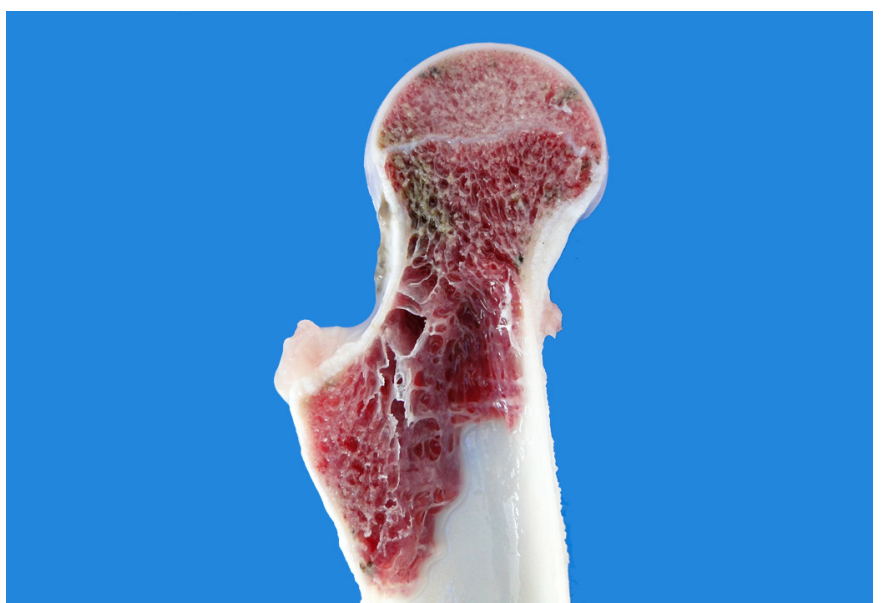

Fig.3. Osteoporose em caprino. Fêmur proximal. Cabra 4, apresentando osso cortical marcadamente fino e depleção do osso esponjoso metafisário.

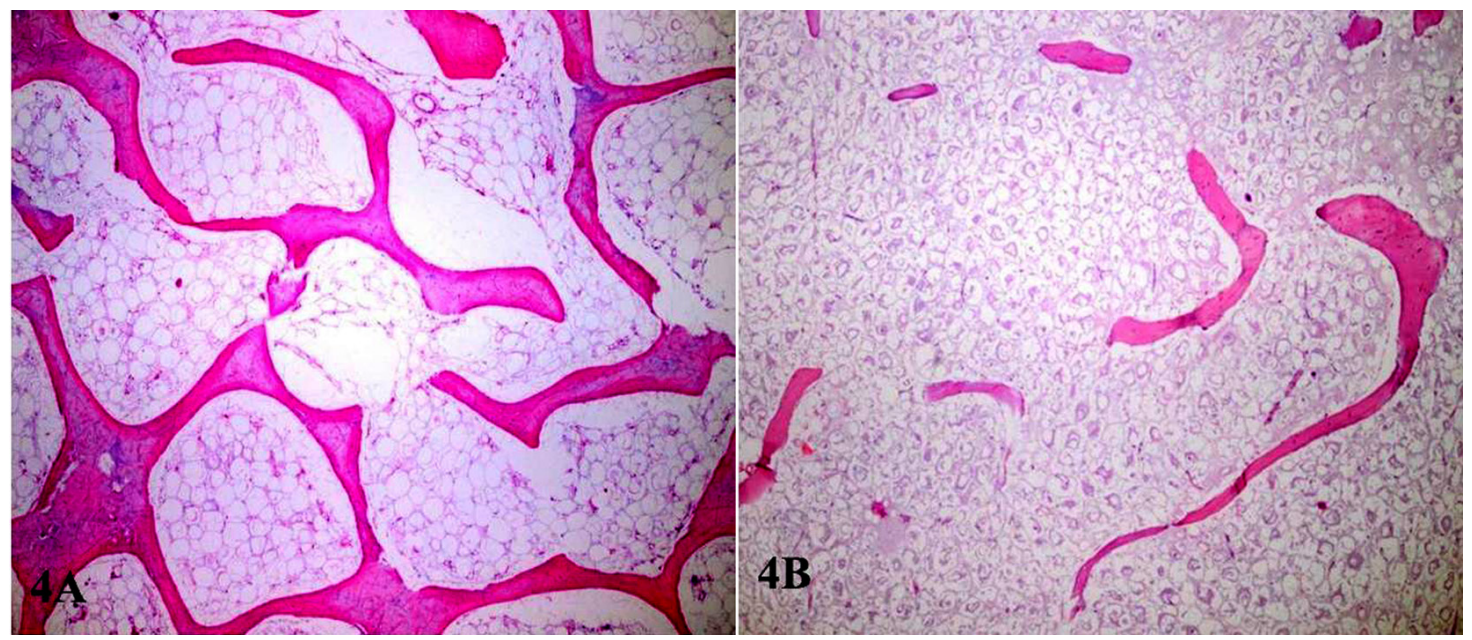

Fig.4. Osteoporose em caprino. Úmero proximal. (A) Cabra normal. HE, obj. 4x. (B) Cabra 4, trabéculas ósseas acentuadamente reduzidas em número e em espessura. HE, obj.4x.

Haemonchus sp. e Cooperia sp. com $72 \%$ e $28 \%$, respectivamente.

Na necropsia, as cinco cabras estavam em mau estado corporal (desnutrição), com mucosas pálidas (anemia), atrofia serosa da gordura epicárdica e ausência ou mínima quantidade de tecido adiposo subcutâneo e abdominal. Marcada atrofia serosa da gordura da medula óssea foi evidenciada na superfície de corte dos ossos longos. As Cabras 3, 4 e 5 continham numerosos exemplares de Haemonchus sp. no abomaso. 0 fígado e os rins estavam levemente pálidos. Na necropsia da Cabra 1, observaram-se também placas rugosas multifocais (mineralização) na artéria aorta torácica e abdominal e em suas ramificações e edema pulmonar acentuado (lesão atribuída como causa da morte dessa cabra).

As principais alterações ósseas macroscópicas nos ossos examinados (úmero, rádio, fêmur, tíbia e vértebras lombares) encontram-se no Quadro 3. Havia marcada depleção do osso esponjoso, às vezes formando cavitações, e o córtex ósseo estava muito fino (Fig.1-3). Além dos ossos mencio-

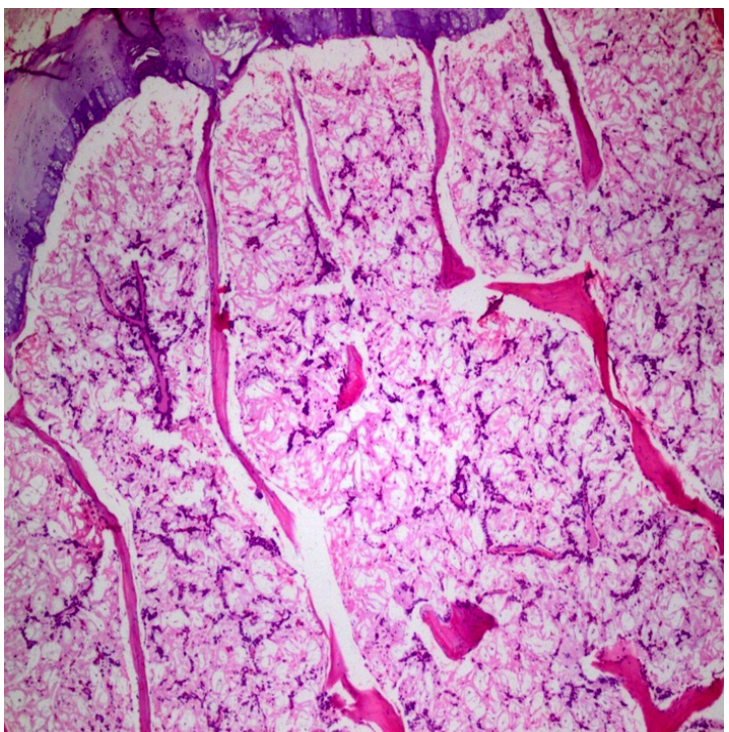

Fig.5. Osteoporose em caprino. Fêmur dis tal. Cabra 1, trabéculas ósseas acentuadamente reduzidas em espessura. HE, obj.4x. 
nados no Quadro 3, também foram observados diferentes graus de depleção do osso esponjoso e redução na espessura do osso cortical na escápula, mandíbula, crista ilíaca, metacarpo e metatarso nas Cabras 2-5.

Microscopicamente, nas regiões avaliadas (extremidades proximais do úmero e tíbia, extremidades distais do rádio e fêmur e corpos vertebrais lombares) foi observada redução moderada a acentuada do número e espessura das trabéculas ósseas nas epífises e metáfises dos ossos longos e nas vértebras (Fig. 4 e 5). Nas Cabras 2-5 foi observada degeneração e necrose hepatocelular centrolobular e mediozonal. Na avaliação histológica da medula óssea, dois dos cinco caprinos não apresentaram alterações (Cabras 1 e 2). Nos outros três caprinos havia uma variável hiperplasia do componente eritroide (Cabras 3, 4 e 5). Essa hiperplasia era leve (Cabra 3) à acentuada (Cabra 5). Nesses três caprinos havia substituição gradual da medula gordurosa por precursores eritroides.

\section{DISCUSSÃO}

O diagnóstico de osteoporose nas cinco cabras deste relato foi baseado nos sinais clínicos e nos achados macroscópicos e histopatológicos. Doenças ósseas metabólicas diferem na sua patogênese, porém os sinais clínicos são semelhantes (Braun et al. 2009), podendo surgir dificuldades no diagnóstico clínico diferencial. As doenças ósseas mais comuns em ruminantes incluem raquitismo/osteomalacia, osteodistrofia fibrosa e calcinose enzoótica (Stover 2006). Dificuldades de locomoção e de permanecer em estação foram os principais sinais clínicos observados nas cabras deste estudo e são comumente vistos em animais acometidos por doenças músculo-esqueléticas (Radostits et al. 2007).

Na necropsia da Cabra 1 foi observada mineralização da artéria aorta e suas ramificações, achado altamente sugestivo de calcinose enzoótica (Peixoto et al. 2012). Inicialmente suspeitou-se de intoxicação por Nierembergia veitchii, planta calcinogênica mais comum na região (Rissi et al. 2007). Entretanto, descartou-se esse diagnóstico após a avaliação macroscópica dos ossos desta cabra, que não tinham lesões ósseas compatíveis com calcinose enzoótica. Isto foi corroborado após a visita à propriedade, devido à ausência da planta, e após a necropsia das outras quatro cabras que não apresentaram mineralização arterial. Mineralização arterial também é descrita em doenças debilitantes crônicas (por ex.: paratuberculose) (Miller et al. 2012). Entretanto, não foi possível determinar a causa primária da lesão arterial vista na Cabra 1, que era nascida na propriedade.

Anemia foi uma alteração clínico-patológica importante nas cabras deste estudo, porém não relacionada à osteoporose, mas sim ao parasitismo observado. $\mathrm{O}$ valor da $\mathrm{Hb}$ estava marcadamente abaixo $(2,1-5,2 \mathrm{~g} / \mathrm{dL})$ do valor de referência $(8-12 \mathrm{~g} / \mathrm{dL})$ e foi associado ao parasitismo abomasal, pois $72 \%$ das larvas na coprocultura eram de $\mathrm{Ha}$ emonchus sp., principal nematódeo hematófago causador de anemia em pequenos ruminantes (Berne et al. 2007). A anemia também foi responsável pela degeneração e necrose hepatocelular centrolobular e mediozonal observada nas Cabras 2 a 5.
Sabe-se que as deficiências de minerais como Ca, $\mathrm{P}$ e cobre $(\mathrm{Cu})$ podem induzir à osteoporose de origem nutricional em animais, geralmente por deficiência de todos esses nutrientes juntos e, raramente, por deficiência de um nutriente isolado (Thompson 2007). A concentração de Ca estava levemente diminuída nas Cabras 2 a $4(6,8-$ $8,8 \mathrm{mg} / \mathrm{dL}$; valor de referência $=8,9-11,7 \mathrm{mg} / \mathrm{dL}$ ) e a de $\mathrm{P}$ estava moderadamente diminuída apenas na Cabra 4. Os níveis de Cu não foram determinados. Osteoporose por deficiência de $\mathrm{Cu}$ não foi descrita em caprinos; recentemente foi descrita em búfalos, porém associada a outros fatores (Pereira \& Cardoso 2010). A deficiência marcada de Ca e P como causadora de osteoporose em animais já foi relatada em cordeiros (Thamsborg \& Hauge 2001) e em caprinos (Braun et al. 2009) e associada ao alto parasitismo gastrintestinal nesses dois estudos. Nos cordeiros afetados foi observado acentuado parasitismo por Ostertagia spp. e Trichostrongylus spp. Já nos caprinos, apenas espécies de Trichostrongylus foram identificadas. 0 parasitismo por esses nematódeos induz má absorção desses minerais, causando assim a deficiência. Estudos experimentais também comprovaram a indução de osteoporose em cordeiros por acentuado parasitismo por esses dois nematódeos (Sykes et al. 1975, Sykes et al. 1977).

Apesar de estarem parasitadas por Haemonchus sp. e Cooperia sp., conforme a necropsia e a coprocultura, as cabras deste estudo não mostraram alterações marcantes nos valores de Ca e P. Esses resultados tornaram pouco provável que o parasitismo gastrintestinal, associado à deficiência mineral, seja a causa primária da osteoporose das cabras deste estudo, porém não descartam uma contribuição secundária. Entretanto, o parasitismo certamente contribuiu para a debilidade dessas cabras.

Os valores da FA sérica das Cabras 2-5 estavam abaixo (entre 20 e 70 U/L) do valor de referência (93-387 U/L). Esse achado foi semelhante em cordeiros com osteoporose devido ao parasitismo gastrintestinal e foi relacionado à formação ou remodelamento ósseos reduzidos (Thamsborg \& Hauge 2001). Em humanos, a atividade da FA é o índice bioquímico mais comumente utilizado para detectar doenças ósseas metabólicas, particularmente em doenças relacionadas à formação óssea (Rosenberg 2005). Atividade reduzida da FA também foi vista na coccidiose em caprinos (Dash et al. 1991) e bovinos (Holst \& Svensson 1994). Consumo reduzido de alimento também pode contribuir para a atividade reduzida da FA (Thamsborg \& Hauge 2001) e pode ser a principal explicação para a redução na FA nas cabras deste estudo, que apresentavam marcada desnutrição.

A atividade da CK estava levemente elevada nas Cabras 2 e 3. Achado semelhante foi descrito na osteoporose de caprinos por deficiência de Ca e $\mathrm{P}$ e atribuído à lesão muscular causada pelo decúbito frequente em vez de doença muscular primária (Braun et al 2009).

Os achados macroscópicos observados em todas as cabras foram semelhantes aos descritos na literatura (Jee \& Yao 2001, Zarrinkalam et al. 2009, Ding et al. 2010). Os principais ossos afetados foram: úmero, rádio, fêmur, tíbia e corpos vertebrais. Diferentes graus de depleção do osso esponjoso (porosidade) e redução da espessura do osso 
cortical foram observados em todas as cabras. Em algumas cabras foram observadas cavitações no osso esponjoso dos ossos longos e vértebras, achado semelhante à osteoropose descrita em búfalos (Pereira \& Cardoso 2010). As lesões macroscópicas mais marcantes de osteoporose são vistas em ossos onde predomina o osso trabecular, provavelmente porque o osso trabecular tem maior razão de área de superfície pelo volume do que o osso cortical e é reabsorvido mais rapidamente (Rosenberg 2005). Nos ossos citados acima, o osso trabecular é predominante, justificando assim seu maior comprometimento.

No exame histopatológico, foram analisadas as extremidades proximais do úmero e tíbia, extremidades distais do rádio e fêmur e corpos vertebrais lombares onde foi observada diminuição do número e espessura das trabéculas ósseas, semelhante ao que é descrito na literatura em casos de osteoporose (Jee \& Yao 2001, Zarrinkalam et al. 2009, Ding et al. 2010). Esses locais, com exceção das vértebras lombares, foram escolhidos, pois são locais de rápido crescimento ou movimento e indicados para análise quando se suspeita de doença óssea metabólica (Thompson 2007). As vértebras lombares foram também escolhidas, pois são locais frequentes de fraturas em humanos com osteoporose (Rosenberg 2005). Microscopicamente, ossos severamente afetados por osteoporose não necessariamente fornecem informações adicionais, já que a depleção do tecido ósseo pode ser estabelecida baseada na macroscopia. A histomorfometria quantitativa pode ser de valor para o diagnóstico da osteoporose em casos duvidosos, mas é essencialmente uma ferramenta de pesquisa, em vez de ser utilizada no diagnóstico de rotina. Entretanto, a microscopia permite examinar a qualidade do osso, permitindo assim diferenciar de outras doenças ósseas metabólicas (Thompson 2007).

Considerando-se os achados clínico-patológicos e os demais aspectos discutidos anteriormente, a causa mais provável de osteoporose nas cabras deste estudo foi a desnutrição. Isto é corroborado pela marcada atrofia serosa da gordura medular observada nas cinco cabras, o qual é um aspecto adicional comumente descrito na osteoporose induzida por desnutrição em animais (Thompson 2007). Em animais de fazenda, a osteoporose por desnutrição tem um papel importante quando há redução do consumo de alimentos e falta de uma ração balanceada na dieta (Thompson 2007). As cabras do presente estudo eram magras e desnutridas, sendo que a alimentação era à base de pastoreio em campo nativo com alta densidade populacional. 0 proprietário foi orientado quanto ao manejo e sanidade dos caprinos e o problema foi solucionado, sem ocorrência de novos casos.

Em animais desnutridos, o mecanismo de osteoporose é considerado complexo, mas acredita-se que a falta de proteína e energia na dieta provavelmente contribuem direta ou indiretamente. Sabe-se que efeitos da desnutrição no esqueleto são maiores em jovens em crescimento do que nos adultos (Reilly et al. 2002). Com exceção da Cabra 2 (com seis anos), as demais cabras afetadas eram jovens, com idades variando de seis a 10 meses.

A patogênese da osteoporose por desnutrição, em termos de desequilíbrio no remodelamento, não é completa- mente definida. Acredita-se que a formação óssea deficiente possa ser a responsável, porém o nível de reabsorção óssea durante a desnutrição é desconhecido (Thompson 2007). A histologia, embora não permita estabelecer um diagnóstico etiológico, pode prover uma indicação da patogênese da perda óssea. Há evidências de que a osteoporose evoluindo de reabsorção óssea aumentada é caracterizada por um declínio no número de trabéculas, enquanto que na osteoporose evoluindo de má formação óssea, o número de trabéculas é normal, porém elas são finas (Thompson 2007). Nos casos aqui estudados foram observados ambos os aspectos, diminuição no número e na espessura das trabéculas, permitindo inferir que ambos os mecanismos (má formação óssea e reabsorção óssea aumentada) contribuíram para sua ocorrência, o que já foi observado na osteoporose (Thompson 2007). Outros mecanismos de osteoporose são conhecidos, e apesar de serem frequentes em humanos, são incomuns em animais e incluem a osteoporose por senilidade, por complicação de doença inflamatória intestinal e a induzida por corticosteroides (Carlson \& Weisbrode 2012).

\section{CONCLUSÕES}

As principais conclusões obtidas neste estudo foram:

- Claudicação, fraqueza, decúbito frequente e dificuldade em manter-se em estação foram os sinais clínicos sugestivos de osteoporose;

- Os achados clínico-patológicos indicaram que a osteoporose observada provavelmente foi causada pela desnutrição;

- As alterações ósseas (diminuição no número e na espessura das trabéculas do osso esponjoso) sugerem que ambos os mecanismos, má formação óssea e reabsorção óssea aumentada, contribuíram para a ocorrência de osteoporose nos caprinos deste estudo.

Agradecimentos.- F.B. Rosa é bolsista do Conselho Nacional de Desenvolvimento Científico e Tecnológico (CNPq). G.J.N. de Galiza é bolsista da Coordenação de Aperfeiçoamento de Pessoal de Nível Superior (CAPES). R.A. Caprioli e T.M. Silva são bolsistas PIBIC/CNPq. G.D. Kommers é bolsista de produtividade em pesquisa (PQ-2) do CNPq.

\section{REFERÊNCIAS}

Adachi J.D. 2009. Glucocorticoid-induced osteoporosis. Osteoporos. Int. 20:239-240.

Berne M.E.A., Vieira L.S. \& Costa C.A.F. 2007. Parasitoses por nematódeos gastrintestinais em caprinos, p.604-616. In: Riet-Correa F., Schild A.L., Lemos R.A.A. \& Borges J.R.J. (Eds), Doenças de Ruminantes e Equídeos. Vol.1. 3aㅡ ed. Pallotti, Santa Maria, RS.

Braun U., Ohlerth S., Liesegang A., Forster E., Gorber U., Tschuor A., Bearth G., Muntwyler J., Wiederkehr D. \& Ossent P. 2009. Osteoporosis in goats associated with phosphorus and calcium deficiency. Vet. Rec. 164:211-213.

Carlson C.S. \& Weisbrode S.E. 2012. Bones, joints, tendons, and ligaments, p.920-971. In: Zachary J.F. \& McGavin M.D. (Eds), Pathologic Basis of Veterinary Disease. $5^{\text {th }}$ ed. Elsevier, St Louis.

Dash B., Misra S.C. \& Panda M.R. 1991. A note on serum enzyme activity in experimental coccidiosis in kids. Indian Vet. J. 68:185-186.

Ding M., Cheng L., Bollen P., Schwarz P. \& Overgaard S. 2010. Glucocorticoid induced osteopenia in cancellous bone of sheep. Spine 35(4):363-370.

Egermann M., Goldhahn J. \& Schneider E. 2005. Animal models for fracture treatment in osteoporosis. Osteoporos. Int. 16(2):129-138. 
Gordon H. \& Whitlock H.V. 1939. A new technique for counting nematode eggs in sheep faeces. J. Counc. Sci. Ind. Res., Austrália, 12:50-52.

Holst H. \& Svensson C. 1994. Changes in the blood composition of calves during experimental and natural infections with Eimeria alabamensis. Res. Vet. Sci. 57:377-383.

Jee W.S.S. \& Yao W. 2001. Overview: animal models of osteopenia and osteoporosis. J. Musculoskel. Neuron Interact. 1(3):193-207.

Kaneko J.J., Harvey J.W. \& Bruss M.L. 2008. Appendix VIII blood analyte reference values in large animals, p.882-888. In: Kaneko J.J., Harvey J.W. \& Bruss M.L. (Eds), Clinical Biochemistry of Domestic Animals. $6^{\text {th }}$ ed. Elsevier, San Diego.

Li Z., Peng S., Pan H., Tang B., Lam R.W.M. \& Lu W.W. 2012. Microarchitecture and nanomechanical properties of trabecular bone after strontium administration in osteoporotic goats. Biol. Trace Elem. Res. 145:39-46.

Miller L.M., Van Vleet J.F. \& Gal A. 2012. Cardiovascular system and lymphatic vessels, p.539-588. In: Zachary J.F. \& McGavin M.D. (Eds), Pathologic Basis of Veterinary Disease. $5^{\text {th }}$ ed. Elsevier, St Louis.

Peixoto P.V., Klem M.A.P., França T.N. \& Nogueira V.A. 2012. Hipervitaminose D em animais. Pesq. Vet. Bras. 32(7):573-594.

Pereira W.L.A. \& Cardoso E.C. 2010. Osteoporose em bubalinos em relação à idade, à condição clínica animal e ao estado físico-químico ósseo e do cobre hepático. Braz. J. Vet. Res. Anim. Sci. 47(2):159-167.

Radostits O.M., Gay C.C., Hinchcliff K.W. \& Constable P.D. 2007. Diseases of bones, p.632-637. In: Ibid. (Eds), Veterinary Medicine: a textbook of the diseases of cattle, horses, sheep, pigs, and goats. $10^{\text {th }}$ ed. Elsevier, Philadelphia.

Reilly L.K., Baird A.N. \& Pugh D.G. 2002. Diseases of the musculoskeletal system, p.223-254. In: Pugh D.G. (Ed.), Sheep and Goat Medicine. W.B. Saunders, Philadelphia.

Rissi D.R., Rech R.R., Pierezan F., Kommers G.D. \& Barros C.S.L. 2007. Intoxicação em ovinos por Nierembergia veitchii: observações em quatro surtos. Ciência Rural 37(5):1393-1398.
Roberts F.H. \& O'Sullivan P.J. 1950. Methods for egg counts and larval cultures for strongyles infesting the gastro-intestinal tract of cattle. Aust. J. Agric. Res. 1:99-102.

Rosa F.B., Galiza G.J.N., Lucena R.B., Silva T.M., Caprioli R.A., Barros C.S.L., Fighera R.A. \& Kommers G.D. 2013. Doenças de caprinos diagnosticadas na região Central no Rio Grande do Sul: 114 casos. Pesq. Vet. Bras. 33(2):199-204.

Rosenberg A.E. 2005. Ossos, articulações e tumores de tecidos moles, p.1331-1385. In: Kumar V., Abbas A.K. \& Fausto N. (Eds), Robbins e Cotran Patologia-Bases Patológicas das Doenças. 7a ed. Elsevier, Rio de Janeiro.

Stover S.M. 2006. Enfermidades dos ossos, das articulações e dos tecidos conjuntivos, p.1085-1148. In: Smith B.P. (Ed.), Medicina Interna de Grandes Animais. $3^{\text {a }}$ ed. Manole, Barueri, SP.

Sykes A.R., Coop R.L. \& Angus K.W. 1975. Experimental production of osteoporosis in growing lambs by continuous dosing with Trichostrongylus colubriformis larvae. J. Comp. Pathol. 85:549-559.

Sykes A.R., Coop R.L \& Angus K.W. 1977. The influence of chronic Ostertagia circumcincta infection on the skeleton of growing sheep. J. Comp. Pathol. 87:521-529.

Thamsborg S.M. \& Hauge E.M. 2001. Osteopenia and reduced serum alkaline phosphatase activity in grazing lambs naturally infected with gastrointestinal nematodes. J. Comp. Pathol. 125:192-203.

Thompson K. 2007. Bones and joints, p.1-184. In: Maxie M.G. (Ed.), Jubb, Kennedy and Palmer's Pathology of Domestic Animals. Vol.1. $5^{\text {th }}$ ed. Elsevier, Philadelphia.

Veigel E., Moore R.J., Zarrinkalam M.R., Schulze D., Sauerbier S., Schmelzeisen R. \& Voss P.J. 2011. Osteopenia in the maxillofacial area: a study in sheep. Osteoporos. Int. 22:1115-1121.

Zarrinkalam M.R., Beard H., Schultz C.G. \& Moore R.J. 2009. Validation of the sheep as a large animal model for the study of vertebral osteoporosis. Eur. Spine J. 18:244-253. 